\title{
Effects of the senior welfare center exercise program on body shape, physical fitness level, and cardiovascular health-related factors in old man from Korean rural areas
}

\author{
Hey-Young Joo', Joon-Young Park², Hyun-Seung Rhyu',** \\ 'Department of Sports Medicine, Dankook University, Cheonan, Korea \\ 2Department of Kinesiology, College of Public Health \& Cardiovascular Research Center, Lewis Katz School of Medicine, Temple University, Philadelphia, PA, USA \\ ${ }^{3}$ Department of Physical Education, Jungwon University, Goesan, Korea
}

The purpose of this study was to investigate changes in body shape, physical fitness, and cardiovascular health-related factors after a 1 -year combined exercise program in rural old men. Subjects were fourteen old men with more than 65 years of age living in Korean rural areas. The combined exercise program consisted of 90-min dynamic and static exercise sessions at a frequency of 3 days per week. Body shape (body weight [BW], body fat percentage [\%BF], muscle mass [MM], body mass index [BMI], waist hip ratio [WHR]) and physical fitness levels (grip strength, standing up-right, one leg standing, sit and reach, and 2-min walking) were measured before, 6 months and 1 year after the program started. Cardiovascular health-related factors, including blood glucose, systolic blood pressure (SBP), diastolic blood pressure (DBP), total cholesterol (TC), low-density lipoprotein cholesterol
(LDL-c), high-density lipoprotein cholesterol (HDL-c), and triglyceride (TG) were measured. There were no significant changes in BW, BMI, $\% \mathrm{BF}$, and $\mathrm{MM}$ after the training. WHR was significantly decreased at 6 months and 1-year follow-up points compared to baseline. There was no statistically significant difference in grip strength, but there was a significant increase after 6 months and 1 year after standing up right, one leg standing, sit and reach, and 2-min walking tests. There were no significant differences in the levels of glucose, SBP, DBP, TC, LDL-C, and $\mathrm{TG}$, but there was a significant increase in HDL-c after 1-year.

Keywords: Body shape, Physical fitness, Cardiovascular health-related factors, Combined exercise training program, Korean rural areas, Old men

\section{INTRODUCTION}

Aging is a process in which the structure and function of the body gradually deteriorates and the sensitivity to diseases and death increases drastically as the age increases. Carmona and Michan (2016) reviews that the overall vitality of the body is reduced and all physiological functions are impaired in advancing age. For example, the protein synthesis capacity of cells decreases, immune function decreases, muscle strength is decreased, fat content in the body is increased, bone density is decreased, and bone is weakened. In this way, various secondary diseases occur due to the phenomenon of aging process, among which diseases such as metabolic diseases, dementia, and falls are classified as the most com-

mon diseases in the old people (Prince et al., 2015). Methods to prevent such diseases are being studied, especially drugs, nutrition, and exercise habits.

In particular, exercise habits are known to prevent aging as well as to improve physical fitness and reduce the incidence of disease (Ngandu et al., 2015). As a welfare service, the provision of exercise programs has contributed greatly to the improvement of the quality of life and the health promotion of the old people. According to Lee et al. (2006), the old people aged 65 and over reported high levels of quality of life and high interest in health education programs in the senior centers and public health centers. Drewnowski and Evans (2001) recommended nutritional habits such as low-calorie diet, low-fat diet, low-cholesterol diet, low-sodium

${ }^{*}$ Corresponding author: Hyun-Seung Rhyu (D) https://orcid.org/0000-0002-4987-7482 Department of Physical Education, Jungwon University, 85 Munmu-ro,

Goesan-eup, Goesan 28024, Korea

E-mail: rhyuhs@jwu.ac.kr

Received: February 12, 2019 / Accepted: March 23, 2019
This is an Open Access article distributed under the terms of the Creative Commons Attribution Non-Commercial License (http://creativecommons.org/licenses/by-nc/4.0/) which permits unrestricted non-commercial use, distribution, and reproduction in any medium, provided the original work is properly cited. 
diet, high- fiber diet, vitamins and minerals, and physical activity habits such as walking and combined exercise programs. In addition, it has been suggested that the adequate levels of psychological and financial stabilities and should be provided in order to improve the quality of life in senior. A number of studies showed the efficacy of exercise programs in old people. Kim and O'sullivan (2013) reported that weight and body fat were decreased, and strength, flexibility, agility and balance were improved after a 12week aqua aerobic therapy exercise in old women. Belza et al. (2006) showed similar benefits of exercise program which includes community-based physical activity programs for old people.

In this particular study, the effectiveness of the exercise program was assessed through the senior fitness test at pre-, 4-month, and 8-month follow-up periods. As a result, all positive results were fund in eight-foot up-and-go, 30-sec stand, arm curl, self-rated health, medical outcomes study short-form- 12 , mental mean $\%$. $\mathrm{He}$ also reported that these physical activity programs reduce cardiovascular risk factors and are effective in preventing metabolic diseases such as diabetes and hypertension. In addition, a number of studies have reported that participation in the senior's exercise program improves cardiovascular health-related factors (Blumenthal et al., 1989; Brochu et al., 2000; Fletcher et al., 1996). However, there is a lack of research on the exercise program for the old people in rural areas, fishing areas and mountainous areas. In some public health centers and welfare centers, the senior exercise program is being implemented but it is operated by dance sports or recreational programs.

The purpose of this study was to investigate the effects of a combined exercise program (stretching, strength training, aerobic exercise, new-Sports activity) performed within a geriatric welfare center on body shape, physical fitness, and cardiovascular healthrelated factors in old men living in Korean rural areas. The goal of this study was to establish exercise programs for the old people who have limited access to exercise therapy and preventative services due to a poor public transport system and suboptimal residential areas.

\section{MATERIALS AND METHODS}

\section{Participants}

This study was performed in 14 old men aged 65 or older (69.47 \pm 5.89$)$ who had no specific diseases living in $\mathrm{G}$ rural areas. This study was approved by the Institutional Review Board of Jungwon University (approval number: 104429-HR-201901-02202). The applicants who voluntarily participated in the senior
Table 1. The characteristics of the subjects

\begin{tabular}{lr} 
Variable & Mean \pm SD \\
\hline Age $(\mathrm{yr})$ & $69.47 \pm 5.89$ \\
Height $(\mathrm{cm})$ & $166.07 \pm 5.37$ \\
Weight $(\mathrm{kg})$ & $69.22 \pm 7.89$ \\
Body mass index $\left(\mathrm{kg} / \mathrm{m}^{2}\right)$ & $25.22 \pm 3.13$ \\
\hline
\end{tabular}

$\mathrm{SD}$, standard deviation.

welfare center combined exercise program were selected. Physical characteristics of the subjects are listed in Table 1.

\section{Experimental procedures \\ Evaluation of body shape}

The measurement of body shape was processed after arriving in examination place, removing the carried metals, urinated $30 \mathrm{~min}$ before measurement, and taking 5 min of break in comforting status. Body weight, body mass index (BMI), and \% body fat were assessed using body shape measuring instrument, in-body 720 (Bio-space Co., Seoul, Korea). In addition, waist hip ratio (WHR) was measured using a tape measure method.

\section{Health-related physical fitness tests}

Health-related physical fitness test was measured by using senior fitness test (SFT) as a base. Aerobic capacity was evaluated by measuring the 2-min step test. Muscle strength was evaluated based on the measurement of grip strength using a digital measuring instrument (Model 5401, Takei, Niigata, Japan). Muscle endurance was assessed by measuring the 1-min chair standing. Flexibility was assessed by measuring sit and reach. Balance was assessed by measuring one leg standing.

\section{Cardiovascular health-related factors}

The cardiovascular factors were divided into blood pressure and blood variables. Blood pressure was measured in the left upper arm using a standardized mercury sphygmomanometer. A sufficient stability for $10 \mathrm{~min}$ before measurement was taken and measurement was performed twice at intervals of $5 \mathrm{~min}$. Blood samples were obtained from all subjects before and after the 6 months, 12 months of combined exercise program. Blood samples were collected from the antecubital vein using $22-\mathrm{G}$ needles after 30-min rest following body composition evaluation. The collected blood was subjected to analyses of glucose, total cholesterol (TC), low-density lipoprotein cholesterol (LDL-C), high-density lipoprotein cholesterol (HDL-C), triglyceride (TG). 


\section{Exercise program}

The combined exercise program for the elderly was conducted three times a week for 1 year and $90 \mathrm{~min}$ for each exercise session. Ten min of warm up exercise, $10 \mathrm{~min}$ of cool down exercise, 20 min of resistance exercise, $20 \mathrm{~min}$ of aerobic exercise and $30 \mathrm{~min}$ of new sports exercise were performed. The warm up and cool down exercise were performed by stretching and walking for 10 min at beginning and end of each exercise session. Muscle resistance exercise was carried out in two sets of 10-15 sec of each operation using Thera-band and intensity of exercise was set at $11-$ 13 (light to slightly hard) of rating of perceived exertion (RPE) scale. Aerobic exercise was carried out for $20 \mathrm{~min}$, including walking, cycling and rowing exercises. Exercise intensity was set at $45 \%-60 \%$ of target heart rate. New-sports activities were conducted for $30 \mathrm{~min}$, alternating flying disc golf, floor curling, and stacking programs at a frequency of 3 days a week. The exercise intensity of the program was set at 11-13 (light to slightly hard) using a RPE scale. The detailed combined exercise program is presented in Table 2.

\section{Statistical analyses}

Regarding all of the data that were obtained in this research, the average $(\mathrm{M})$ and the standard deviation were calculated by using the statistical program of IBM SPSS Statistics ver. 22.0 (IBM Co., Armonk, NY, USA). Regarding the difference between the prior and afterwards variables according to the method of the ex-

Table 2. Combined exercise program

\begin{tabular}{|c|c|c|c|}
\hline Variable & Program & Frequency & Intensity \\
\hline Warm-up & Stretching & & RPE 11-13 \\
\hline $\begin{array}{l}\text { Strengthening } \\
\text { training }\end{array}$ & $\begin{array}{l}\text { Chest press } \\
\text { Lateral raise } \\
\text { Shoulder press, arm curl } \\
\text { Squat } \\
\text { Hip abduction } \\
\text { Pelvic lifts } \\
\text { Calf raise } \\
\text { Sit-up }\end{array}$ & $\begin{array}{l}\text { TheraBand } \\
\text { 8-12 rep/3 sets }\end{array}$ & 1RM 45\%-60\% \\
\hline Aerobic exercise & $\begin{array}{l}\text { Walking } \\
\text { Cycling } \\
\text { Rowing }\end{array}$ & $\begin{array}{c}\text { Each for } 20 \text { min } \\
\text { once a week }\end{array}$ & THR 45\%-60\% \\
\hline New-sports & $\begin{array}{l}\text { Flying Disc Golf } \\
\text { Floor curling } \\
\text { Stacker }\end{array}$ & $\begin{array}{c}\text { Each for } 30 \text { min } \\
\text { once a week }\end{array}$ & RPE 11-13 \\
\hline Cool-down & Stretching & & RPE 11-13 \\
\hline
\end{tabular}

$\mathrm{RPE}$, rating of perceived exertion; 1RM, one-repetition maximum; THR, target heart rate. ercise and the time of the measurement, the one-way analysis of variance was carried out. And, in case the significance is recognized, the afterwards verification of Duncan had been carried out. The significance level $(\alpha)$ was set to $P<0.05$.

\section{RESULTS}

Table 3 shows changes in the body shape after the 1-year combined exercise program. WHR $(F=4.311, P=0.020)$ showed a statistically significant change. However, there was no statistically significant change in body weight, BMI, \% body fat, and muscle mass, but showed a positive change due to the progression of the combined exercise program.

Table 4 shows changes in fitness factors after the 1-year combined exercise program. Statistically significant changes were observed in 1 -min chair stand $(F=11.470, P=0.001)$, sit and reach $(F=5.570, P=0.007), 2$-min step test $(F=12.150, P=0.001)$. However, there was no statistically significant change in grip strength, but it showed a positive change due to the progress of

Table 3. Changes in body shape according to combined exercise program

\begin{tabular}{|c|c|c|c|c|c|}
\hline Variable & $P E^{a}$ & $6 \mathrm{ME}^{\mathrm{b}}$ & $12 \mathrm{ME}^{\mathrm{c}}$ & F-value & posthoc \\
\hline Body weight (kg) & $69.22 \pm 7.89$ & $68.29 \pm 7.86$ & $67.62 \pm 7.69$ & 0.146 & 0.864 \\
\hline $\mathrm{BMI}\left(\mathrm{kg} / \mathrm{m}^{2}\right)$ & $25.22 \pm 3.13$ & $24.69 \pm 3.13$ & $24.21 \pm 3.14$ & 0.361 & 0.699 \\
\hline$\%$ Body fat (\%) & $25.78 \pm 6.25$ & $25.17 \pm 6.05$ & $24.63 \pm 6.03$ & 0.123 & 0.885 \\
\hline Muscle mass (kg) & $28.67 \pm 5.22$ & $29.36 \pm 5.08$ & $30.49 \pm 5.05$ & 0.452 & 0.640 \\
\hline WHR & $0.94 \pm 0.040$ & $0.91 \pm 0.036$ & $0.89 \pm 0.036$ & 4.311 & $\begin{array}{l}0.020 \\
(a>c)\end{array}$ \\
\hline
\end{tabular}

Values are presented as mean \pm standard deviation.

$\mathrm{PE}$, pre-exercise; $6 \mathrm{ME}, 6$ months of exercise; 12ME, 12 months of exercise; BMI, body mass index; WHR, wrist hip ratio.

Table 4. Changes of elderly physical fitness factors according to combined exercise program

\begin{tabular}{lccccc}
\hline Variable & $\mathrm{PE}^{\mathrm{a}}$ & $6 \mathrm{ME}^{\mathrm{b}}$ & $12 \mathrm{ME}^{\mathrm{c}}$ & F-value & post hoc \\
\hline GS (kg) & $28.05 \pm 6.68$ & $28.95 \pm 6.87$ & $30.21 \pm 6.82$ & 0.359 & 0.701 \\
1MCS (rep/60 sec) & $23.86 \pm 2.77$ & $26.79 \pm 3.07$ & $29.14 \pm 2.93$ & 11.470 & 0.001 \\
& & & & & $(\mathrm{a}<\mathrm{b}, \mathrm{c})$ \\
S\&R (cm) & $2.14 \pm 5.54$ & $5.43 \pm 5.39$ & $8.64 \pm 4.48$ & 5.570 & 0.007 \\
& & & & $(\mathrm{a}<\mathrm{c})$ \\
2MST (rep/2 min) & $98.92 \pm 9.25$ & $106.57 \pm 9.35$ & $116.57 \pm 9.87$ & 12.150 & 0.001 \\
& & & & & $(\mathrm{a}<\mathrm{b}, \mathrm{c})$ \\
OLS (sec) & $5.71 \pm 5.88$ & $8.79 \pm 6.18$ & $15.29 \pm 6.70$ & 8.534 & 0.001 \\
& & & & & $(\mathrm{a}<\mathrm{b}, \mathrm{c})$ \\
\hline
\end{tabular}

Values are presented as mean \pm standard deviation.

PE, pre-exercise; 6ME, 6 months of exercise; 12ME, 12 months of exercise; GS, grip strength; 1MCS, 1-min chair stand; S\&R, sit and reach; 2MST, 2-min step test; OLS, one-leg standing. 
Table 5. Changes in cardiovascular related factors according to combined exercise program

\begin{tabular}{|c|c|c|c|c|c|}
\hline Variable & $P E^{a}$ & $6 \mathrm{ME}^{\mathrm{b}}$ & $12 \mathrm{ME}^{\mathrm{c}}$ & F-value & posthoc \\
\hline $\mathrm{SBP}(\mathrm{mmHg})$ & $145.57 \pm 17.74$ & $136.79 \pm 15.36$ & $130.86 \pm 14.40$ & 3.037 & 0.059 \\
\hline $\mathrm{DBP}(\mathrm{mmHg})$ & $77.79 \pm 11.15$ & $79.71 \pm 8.45$ & $80.93 \pm 9.64$ & 0.366 & 0.696 \\
\hline Glucose (mg/dL) & $137.07 \pm 51.76$ & $127.00 \pm 46.70$ & $114.93 \pm 29.93$ & 0.897 & 0.416 \\
\hline $\mathrm{TC}(\mathrm{mg} / \mathrm{dL})$ & $190.93 \pm 26.37$ & $183.57 \pm 23.28$ & $176.14 \pm 19.10$ & 1.433 & 0.251 \\
\hline LDL-c (mg/dL) & $119.71 \pm 22.16$ & $114.43 \pm 22.57$ & $110.00 \pm 21.94$ & 0.670 & 0.517 \\
\hline HDL-c (mg/dL) & $55.86 \pm 6.89$ & $59.14 \pm 6.83$ & $63.43 \pm 6.42$ & 4.475 & $\begin{array}{l}0.018 \\
(\mathrm{a}<\mathrm{c})\end{array}$ \\
\hline $\mathrm{TG}(\mathrm{mg} / \mathrm{dL})$ & $159.64 \pm 17.73$ & $151.86 \pm 15.37$ & $148.00 \pm 15.62$ & 1.860 & 0.169 \\
\hline
\end{tabular}

Values are presented as mean \pm standard deviation.

PE, pre-exercise; 6ME, 6 months of exercise; 12ME, 12 months of exercise; SBP, systolic blood pressure; DBP, diastolic blood pressure; TC, total cholesterol; LDL-C, low-density lipoprotein; HDL-c, high-density lipoprotein; TG, triglyceride.

the combined exercise program.

Table 5 shows changes in cardiovascular health-related factors after the 1-year combined exercise program. HDL-c $(F=4.475$, $P=0.018$ ) showed statistically significant changes. However, there were no statistically significant changes in all other outcome variables although data showed positive changes after the combined exercise program.

\section{DISCUSSION}

The results of this study showed that 1-year combined exercise program for the old men in rural areas had positive effects on body shape, physical fitness, and cardiovascular-related factors. In terms of body shape, there was a positive change in body weight, body fat percentage, and muscle mass, WHR. Raguso et al. (2006) reported effects of a 3-year leisure-time physical activity in old people. Although there was no change in body weight, there was a slight increase in body fat and a slight decrease in muscle mass. These results were in contrast to the results from this study. Villareal et al. (2006) conducted 3 weekly exercise programs for 6 months in obese older adults. This study also showed that body weight and fat mass were decreased. These results are consistent with the results of this study. Regarding physical fitness levels, positive changes were observed after participating in the 1-year combined exercise program in all the measurement items. Villareal et al. (2006), the physical performance test score, peak oxygen consumption, and functional status questionnaire score were positively changed in the 3-week exercise program for 6 months. These results also showed improvements in strength, walking speed, obstacle course, one-leg limb stance time, and physical survey subscale scores. This is consistent with the results of this study. Final- ly, all of the cardiovascular-related factors showed positive changes as a result of participation in the 1-year combined exercise program. Paoli et al. (2013) conducted a 3-group (high-intensity circuit training, low-intensity circuit training, and endurance training) training for 12 weeks in middle-aged overweight men. As a result, all three groups showed positive changes in body weight, fat mass, lean body mass, DBP, SBP, TG, TC, HDL-c, and LDL-c. This is consistent with the results of this study. A number of studies have reported positive effects of old people participation in exercise program. There are still many places in Korea where a transport system is suboptimal, such as rural areas, mountainous areas, and island areas where the welfare facilities and educational programs are lacking. In order to improve this, it is thought that it is necessary to carry out the exercise program of visiting by base and to produce and distribute exercise program using mobile or internet communication.

\section{CONFLICT OF INTEREST}

No potential conflict of interest relevant to this article was reported.

\section{REFERENCES}

Belza B, Shumway-Cook A, Phelan EA, Williams B, Snyder SJ, LoGerfo JP. The effects of a community-based exercise program on function and health in older adults: The Enhance Fitness Program. J Appl Gerontol 2006;25:291-306.

Blumenthal JA, Emery CF, Madden DJ, George LK, Coleman RE, Riddle MW, McKee DC, Reasoner J, Williams RS. Cardiovascular and behavioral effects of aerobic exercise training in healthy older men and women. J Gerontol 1989;44:M147-157.

Brochu M1, Poehlman ET, Savage P, Fragnoli-Munn K, Ross S, Ades PA. Modest effects of exercise training alone on coronary risk factors and body composition in coronary patients. J Cardiopulm Rehabil 2000; 20:180-188

Carmona JJ, Michan S. Biology of healthy aging and longevity. Rev Invest Clin 2016;68:7-16.

Drewnowski A, Evans WJ. Nutrition, physical activity, and quality of life in older adults: summary. J Gerontol A Biol Sci Med Sci 2001;56 Spec No 2:89-94.

Fletcher GF, Balady G, Blair SN, Blumenthal J, Caspersen C, Chaitman B, Epstein S, Sivarajan Froelicher ES, Froelicher VF, Pina IL, Pollock ML. Statement on exercise: benefits and recommendations for physical activity programs for all Americans. A statement for health profession- 
als by the Committee on Exercise and Cardiac Rehabilitation of the Council on Clinical Cardiology, American Heart Association. Circulation 1996;94:857-862.

Kim SB, O'sullivan DM. Effects of aqua aerobic therapy exercise for older adults on muscular strength, agility and balance to prevent falling during gait. J Phys Ther Sci 2013;25:923-927.

Lee TW, Ko IS, Lee KJ. Health promotion behaviors and quality of life among community-dwelling elderly in Korea: a cross-sectional survey. Int J Nurs Stud 2006;43:293-300.

Ngandu T, Lehtisalo J, Solomon A, Levälahti E, Ahtiluoto S, Antikainen R, Bäckman L, Hänninen T, Jula A, Laatikainen T, Lindström J, Mangialasche F, Paajanen T, Pajala S, Peltonen M, Rauramaa R, StigsdotterNeely A, Strandberg T, Tuomilehto J, Soininen H, Kivipelto M. A 2 year multidomain intervention of diet, exercise, cognitive training, and vascular risk monitoring versus control to prevent cognitive decline in at-risk elderly people (FINGER): a randomised controlled tri- al. Lancet 2015;385:2255-2263.

Paoli A, Pacelli QF, Moro T, Marcolin G, Neri M, Battaglia G, Sergi G, Bolzetta F, Bianco A. Effects of high-intensity circuit training, low-intensity circuit training and endurance training on blood pressure and lipoproteins in middle-aged overweight men. Lipids Health Dis 2013;12: 131.

Prince MJ, Wu F, Guo Y, Gutierrez Robledo LM, O'Donnell M, Sullivan R, Yusuf S. The burden of disease in older people and implications for health policy and practice. Lancet 2015;385:549-562.

Raguso CA, Kyle U, Kossovsky MP, Roynette C, Paoloni-Giacobino A, Hans D, Genton L, Pichard C. A 3-year longitudinal study on body composition changes in the elderly: role of physical exercise. Clin Nutr 2006;25:573-580.

Villareal DT, Banks M, Sinacore DR, Siener C, Klein S. Effect of weight loss and exercise on frailty in obese older adults. Arch Intern Med 2006; 166:860-866. 